\title{
Atenção psicossocial e bem viver: relato de experiência de um Projeto Terapêutico Singular pelas dimensões da Felicidade Interna Bruta
}

Psychosocial care and good living: experience report of a Singular
Therapeutic Project by the dimensions of Gross National Happiness

Roberto Tykanori Kinoshita', Alexandre Teixeira Trino ${ }^{2}$, Cristina Soares Guimarães ${ }^{2}$, Carolina

Aires de Castro ${ }^{3}$, Christiane Moema Alves Sampaio Prado ${ }^{3}$

DOI: 10.1590/0103-11042020E326

RESUMO Este artigo é um relato de experiência da elaboração e implantação de um Projeto Terapêutico Singular (PTS) no Centro de Atenção Psicossocial (Caps) na cidade do Rio de Janeiro. Aborda-se o modelo de atenção adotados no Caps a partir do seu projeto político-institucional, que se destaca pela organização do cuidado psicossocial em torno de processos de trabalho instituídos pela incorporação do PTS por meio da Felicidade Interna Bruta (FIB) e pelo conceito de bem viver. Como em um estudo de caso de caráter exploratório, descrevem-se, por intermédio do conceito de sociomaterialidade, inovações na organização e práticas de cuidado. O PTS é apresentado tanto pela dimensão instrumental quanto social, por meio do protagonismo de gestores, profissionais e usuários no desafio de elaborar uma tecnologia de cuidado a partir de bases diferenciadas e por pressupostos teóricos e práticos que fazem dialogar as diretrizes basilares da atenção psicossocial com as dimensões da FIB. A culminância dessa estratégia visa à formulação de projetos para a felicidade pelo PTS, como uma aposta na reflexão do contexto atual de vida dos usuários do Caps e suas possibilidades de novas subjetividades de sujeitos/cidadãos proativos pelo bem viver no território e na comunidade onde habitam.

PALAVRAS-CHAVE Serviços de saúde mental. Saúde mental. Felicidade.

\begin{abstract}
This article is an experience report of the elaboration and implementation of a Singular Therapeutic Project (PTS) at the Psychosocial Care Center (Caps) in the city of Rio de Janeiro. The Care model adopted in Caps is approached from its political-institutional project, which stands out for the organization of psychosocial care around work processes instituted by the incorporation of PTS through Gross Internal Happiness (FIB) and the concept of good living. As in an exploratory case study, innovations in the organization and care practices are described, through the concept of sociomateriality. The PTS is presented both by the instrumental and social dimension, through the role of managers, professionals and users in the challenge of developing care technology from different bases and by theoretical and practical assumptions that make dialogue with the basic guidelines of psychosocial care with the dimensions of the FIB. The culmination of this strategy aims at formulating projects for happiness by PTS, as a bet on reflecting on the current context of life of Caps users and their possibilities of new subjectivities of proactive subjects / citizens for the wellliving in the territory and the community where they live.
\end{abstract}

KEYWORDS Mental Health Services. Mental health. Hapiness. 


\section{Introdução}

Este artigo é um relato de experiência da elaboração e implantação de um Projeto Terapêutico Singular (PTS) no Centro de Atenção Psicossocial tipo II Carlos Augusto Magal (Caps-Magal), situado no bairro de Manguinhos, na cidade do Rio de Janeiro. Abordaremos a concepção e o modelo de atenção adotados no Caps a partir do seu projeto político-clínico-institucional, que se destaca pela organização do cuidado psicossocial em torno de processos de trabalho instituídos pela incorporação do PTS por meio das dimensões da Felicidade Interna Bruta (FIB) e pelo conceito de bem viver.

A concepção do Bem Viver enaltece o fortalecimento das relações comunitárias e solidárias, os espaços comuns e as mais diversas formas de viver coletivamente, respeitando a diversidade e a natureza [...]. Harmoniza as necessidades da população à conservação da vida, diversidade biológica e equilíbrio de todos os sistemas de vida1(248).

Como em um estudo de caso, de caráter exploratório, iremos descrever a experiência de materializar uma inovação na organização e práticas de atenção psicossocial, a partir de uma construção teórica formulada em 2016 por Kinoshita et al. ${ }^{2}$, por meio dos pressupostos de fazer dialogar concepções da atenção psicossocial com as dimensões da FIB, culminando na construção de uma estratégia que visa ao agenciamento de pessoas e comunidades, na construção e busca de projetos para a Felicidade, como uma aposta baseada na reflexão do contexto atual de vida e suas possibilidades e na produção de subjetividade de sujeitos/cidadãos proativos no seu território, mediante dimensões da FIB orientadoras para implantação de um modelo de PTS no Caps.

Cada pessoa, família ou comunidade é o produto das interações que teve durante a sua história e contexto de vida. Como cada uma dessas histórias é única, para se constituir um projeto futuro é preciso que se elabore um plano pensado de modo muito especial, na medida justa para a pessoa ou coletivo (família/comunidade) e o principal parâmetro de justeza advém da participação da própria pessoa/família/comunidade na formulação e operacionalização do cuidado. Trata-se assim do desafio de desdobrar e aprimorar operativamente as estratégias de cuidado para produção da subjetividade, protagonismo, autonomia das pessoas que são premissas da Atenção Psicossocia|2(52).

Assim, abraçaremos o conceito de sociomaterialidade, como constituição conjunta entre humanos e não humanos, presente em inúmeras linhas de pesquisa, especialmente no campo da Ciência, Tecnologia e Sociedade (CTS). Não se trata somente da experiência de implementação de um PTS em um Caps que estava sendo implantado, mas, antes, tratou-se de orientar a institucionalização de um modelo de cuidado ao mesmo tempo que um 'protocolo' de cuidado foi construído, por parceria, entre gestores e profissionais de saúde.

Em uma perspectiva teórico-conceitual, esse fazer se inspirou, entre outros, nos campos dos estudos sociais da ciência e da tecnologia, além de Law e Mol${ }^{3}$ já citados, também Latour ${ }^{4}$, nos estudos organizacionais Orlikowski ${ }^{5,6}$ e Scott $^{6}$ e no desenvolvimento de sistemas de informação Leonardi ${ }^{7}$, que abraçaram a perspectiva da sociomaterialidade. Aqui, o 'modo de existência das coisas' emerge para suplantar a dicotomia entre os mundos social e material, jogando luz sobre as práticas que produzem novas dinâmicas social e material ${ }^{4}$.

Essa se tornou uma perspectiva apropriada para explicitar as imbricações entre um complexo formado por um objeto/material, um formulário de PTS $^{8}$ pela FIB construído e constituído nos interstícios heterogêneos entre o material e social, surgindo como âncora para as contratualidades do paciente com o território, para as práticas dos profissionais de saúde e para a organização do cuidado no Caps (este formulário encontra-se no link: https://repositorio.observatoriodocuidado. org/handle/handle/2700). 


\section{Mergulho teórico com ação prática: desenhar e experimentar um PTS fundado na FIB}

Inspirados em Paul Singer', economista brasileiro que contribuiu para a divulgação do conceito da FIB no Brasil, o pioneirismo desse projeto teve seu começo em 2015, quando da iniciativa, por parte de gestores e técnicos da política nacional de saúde mental do Ministério da Saúde, de produzir orientações sobre como operar, na prática, com vistas à inclusão de pessoas em condições de vulnerabilidade na atenção integral à saúde. O projeto de elaboração do 'Caderno de Atenção Básica’ para os Núcleos de Apoio à Saúde da Família (Nasf) tinha como objetivo orientações sobre o cuidado psicossocial aos trabalhadores dessas Equipes de Saúde da Família (EqSF); e, de forma pragmática, buscava propor um cardápio de ofertas de ações que a EqSF/Nasf poderiam realizar para qualificar e fortalecer as ações de saúde mental na atenção básica, baseadas nas dimensões da FIB.

A formulação dessa proposta tomou o PTS como uma tecnologia de cuidado que 'contratualiza' a relação paciente-profissional e norteia entendimentos sobre a prática do cuidado, convida o usuário a traçar projetos para a vida pautados pela significação do seu sofrimento psíquico, para produção de vida e autonomia na sua reinserção social, demonstrando, por ações concretas, possibilidades de reorientações da atenção psicossocial.

Pela via comunitária e territorial e fundado na integralidade, intersetorialidade e sustentabilidade das ações, o texto sobre um PTS, formulado em 2015 para compor o caderno de atenção básica do Nasf do Ministério da Saúde, buscava trazer as nove dimensões articuladas da FIB, orientado por novos fazeres na prática da saúde. A aposta era que essa estratégia fosse capaz de catalisar estratégias de cuidado e de promoção radical de saúde pactuadas nas possibilidades de projetos de vida locais, singulares, de forma transformadora, concreta e pragmática com o usuário e os profissionais da Rede de Atenção Psicossocial (Raps).

No entanto, a transformação para uma crise no cenário político do País naquele momento, em 2015, trouxe consequências e mudanças profundas na gestão do Ministério da Saúde, e o 'Caderno de Atenção Básica' para os Nasf não foi publicado, ficando aquele conteúdo produzido do PTS e a edição da obra em aberto, à espera de novas oportunidades para publicação.

No ano de 2016, surgiu o momento para publicar esse texto por Kinoshita et al. ${ }^{2}$, em formato de capítulo de livro intitulado 'Cuidado em saúde mental: do sofrimento à felicidade', inaugurando o primeiro manuscrito acerca do tema da FIB e a proposta de um PTS a partir de suas dimensões no campo da atenção psicossocial.

Também em 2016, surgiu a oportunidade de unir o adensamento teórico e conceitual produzido com a ação efetiva, e assim formular e experimentar um PTS fundado na $\mathrm{FIB}^{8}$, de forma inovadora, em um território exposto a profundas iniquidades sociais, em um Caps recém-inaugurado na cidade do Rio de Janeiro, em que um dos pesquisadores que formulou o texto ${ }^{2}$ citado acima, exerceria também a função de ser o supervisor clínico institucional do Caps.

Toma-se essa implantação do PTS como um marco, um movimento, em uma emergência de encontros e de saberes que estabelecem a construção do projeto político-clínico-institucional10 do Caps, tanto por meio da concepção do modelo da atenção psicossocial como do seu funcionamento pelo conceito da FIB.

Sobretudo, na incorporação de um PTS como forma de organizar o cuidado aos usuários, iremos explorar os processos de formulação, legitimação e utilização do PTS, atentos a esse acontecimento, delineando a experiência, sua implicação, apropriação, significação e descrevendo o método como compreensão desse evento/acontecimento. 
Aproximar-se ao método é caminhar em direção ao que está em mira. O que se mira é a compreensão do acontecimento no método. A começar de um projeto de pesquisa, em uma perspectiva acontecimental ele é parte integrante do processo como mapa proposicional. Pode-se, então, pensar em uma pesquisa 'sem projeto' nas Veredas do Sertão acontecimento. Pois pesquisar é compreender o acontecimento. Daí os dispositivos necessários de descrição e compreensão do fenômeno/acontecimento investigado. Todos os dispositivos instrumentais pertencentes à oficina de trabalho do pesquisador estão indelevelmente a serviço do acontecimento e não ao contrário ${ }^{11(17)}$.

Igualmente tendo participado como gestor, atuando ativamente na implantação e implementação do referido Caps, o pesquisador, coautor deste manuscrito ${ }^{2}$ e pesquisador desse tema em uma tese de doutoramento, também aproveita aqui os seus próprios registros da vivência a partir de notas escritas em diários de campo e de ádios gravados de sua autoria exclusiva com suas impressões e por meio de seus próprios relatos e de ninguém mais, acerca do trabalho que desenvolveu na supervisão clínico-institucional desse Caps. Tais registros e memórias de diários de campo do trabalho realizado, ora como observador participante, ora como um participante observador, adicionam um caráter etnográfico a essa etapa e são importantes para descrever esse momento.

A defesa de uma modalidade de pesquisa-ação como escopo de uma tese demonstrou que um pesquisador gestor, observador e participante, atuando por meio de um gestor pesquisador, participante e observador, pode gerar conhecimentos e práticas em saúde mental pelo método de uma pesquisa acontecimental10. Assim, as experimentações coletivas com usuários, trabalhadores e gestores, implicados diretamente com a temática da pesquisa nesse Caps, buscaram, de forma diferenciada, a produção de novas subjetivações, mediante processualidade da formulação, apreensão, utilização e legitimação do PTS pelas dimensões da FIB e a possibilidade de conceber estratégias de atenção psicossocial inovadoras e mais inclusivas.

A implantação do Caps e a seleção da equipe de trabalhadores e gestores já operaram preliminarmente ao seu funcionamento, para adequar os objetivos da proposta inovadora ao novo serviço naquele território, observando fatores importantes, como a localização estratégica no território com vistas à articulações intra e intersetoriais e com a comunidade, perfil de profissionais selecionados para essa experiência, formulação do projeto político-clínico-institucional ${ }^{9}$ do ponto de atenção, inclusão de lideranças comunitárias na construção e planejamento de abertura do Caps, entre outros.

Assim, com a inauguração do serviço em outubro de 2016, a supervisão clínico-institucional do Caps, participando semanalmente das reuniões de equipe, teve um papel importante nessa pesquisa, pois toda a concepção e modelo da proposta inovadora de ter um PTS pelas dimensões da $\mathrm{FIB}^{8}$ incluía a necessidade de qualificação do corpo de trabalhadores e gestores, aproveitando o momento inicial do Caps, sem resquícios de modelagens anteriores e pautado pela necessidade de dotar a organização do cuidado do serviço em sinergia com uma atenção psicossocial de base comunitária, pelo conceito de bem viver da FIB.

Foram realizadas inúmeras ações de formação com todos os profissionais, por intermédio das reuniões semanais de equipe, bem como com sessões extras de educação permanente conduzidas pelo supervisor clínico-institucional do Caps, fazendo também o papel de pesquisador. À medida que a direção e os trabalhadores do Caps foram legitimando a proposta do PTS por meio de ações, eles tiveram a liberdade de adequar o formato inicial proposto de PTS, à luz da realidade das demandas e necessidades dos usuários sem, contudo, descaracterizar a concepção do modelo adotado. Pelo contrário, com essa autonomia, mostraram-se mais partícipes da proposta e demostraram, de forma gradual e paulatina, a apropriação do PTS como 
instrumento importante para formulação de projetos para felicidade.

Ressalta-se aqui a realização de diversas estratégias de sensibilização dos pacientes e familiares quanto a orientações referentes ao funcionamento do Caps, em que utilizamos as assembleias semanais de usuários como um espaço potente para construirmos com eles as propostas de ações individuais e coletivas, e entendimentos acerca da organização do cuidado no serviço e no território.

Uma das inovações, nesse sentido, muito induzidas pela concepção desse modelo de PTS pela FIB $^{8}$ foi a incorporação, na equipe do Caps, do agente territorial, profissional com perfil de articulação de redes e agenciamentos no território, morador ou com bastante conhecimento no território de cobertura do serviço e que media com os usuários possibilidades de inserção social e promoção do cuidado no território onde habitam.

No final de um ano de funcionamento do serviço, com mais de 200 usuários cadastrados, já observamos que o Caps atuava com diversas estratégias e dispositivos de cuidado que priorizavam articulações potentes com o território e a comunidade, por meio dessa concepção de cuidado pautada pelo bem viver e pelas dimensões da FIB.

A seguir, abordaremos os pressupostos dessa concepção e modelo acoplado à atenção psicossocial no Caps.

\section{Concepção e modelo: saúde mental e felicidade, uma agenda em construção}

Na perspectiva dessa agenda em construção - a concepção de bem viver como um conceito que a saúde pública vem-se apropriando para produção do cuidado de base comunitária -, utilizamos no Caps os referenciais de um indicador de desenvolvimento sustentável, a FIB, proposta originada em um país localizado na Ásia, no alto da Cordilheira do Himalaia, cuja política teve bastante destaque quando foi aprovada na Assembleia Geral das Nações Unidas, em 2011, colocando a 'felicidade' na prioridade de pautas para políticas públicas do desenvolvimento global a partir de um novo paradigma.

Mas o que mais se assemelha ao conceito do 'Buen Vivir' é o índice de 'Felicidade Interna Bruta', elaborado por um país budista localizado no Himalaia, Butão, que assume uma concepção de vida inspirada em conceitos muito próximos do Bem Viveri(241).

Por essa concepção, sustenta-se que é preciso mudar a estrutura de relações sociais e econômicas a fim de preservar os recursos naturais para gerações futuras, por meio da construção de um novo paradigma de desenvolvimento que não seja mensurado por indicadores macroeconômicos cujo foco está no Produto Interno Bruto (PIB), mas, sim, por analogia e oposição a incluir, nessa agenda, indicadores e dimensões de bem viver, convivência comunitária, boa governança, entre outros e com os quais designou como índice de FIB ${ }^{12}$.

Karma Ura ${ }^{13}$, referência internacional para estudos sobre a FIB no Butão, afirma que a felicidade é, e deve ser, um bem público, já que todos os seres humanos a almejam. Ela não pode ser deixada exclusivamente a cargo de dispositivos e esforços privados. Se o planejamento governamental e, portanto, as condições macroeconômicas da nação forem adversos à felicidade, esse planejamento fracassará enquanto uma meta coletiva. Os governos precisam criar condições conducentes à felicidade, na qual os esforços individuais possam ser bem-sucedidos. A política pública é necessária para educar os cidadãos sobre a felicidade coletiva.

A atual dinâmica social hegemônica tem como base a competição, que alimenta o individualismo, estando estreitamente ligada à estratificação da sociedade, que é promotora das desigualdades sociais tão conhecidas no mundo globalizado. Tal lógica é marcada por um ambiente de intensa disputa por afeto, por reconhecimento e por êxito. Esse 
funcionamento excludente gera alta carga de sofrimento psíquico, tendo a iniquidade social e as dificuldades socioeconômicas importante relação com a saúde mental da população².

A proposta da felicidade nas políticas públicas vem ganhando adesão em alguns países, como Inglaterra, Canadá, França, Tailândia, Butão, Coréia do Norte, Colômbia, Bolívia, Equador, entre outros, citados por diversos estudos e pesquisadores: O'Donnell14, Nery ${ }^{15}$, Stiglitz ${ }^{16}$, Sen $^{17}$, entre outros. Particularmente no campo da saúde, a FIB tem sido tomada como fonte de inspiração e parâmetro para constituir estratégias de atenção à saúde que considerem o sujeito em sua integralidade ${ }^{2}$.

É mais fácil descrever e analisar o sofrimento em vez de fazer o mesmo com a felicidade. Como não é de hábito documentar felicidade há perda progressiva de instrumentos utilizados. Não considerá-la, implica declará-la inexistente e impossíve|18(1).

A FIB apresenta domínios ou dimensões que, no seu conjunto, orientam para ações e estratégias de promoção da melhoria da qualidade de vida nas comunidades e que se coadunam com o conceito de bem viver, são elas: Bem-Estar Psicológico; Padrões de Vida; Boa Governança; Saúde; Educação; Vitalidade Comunitária; Diversidade Cultural e Resiliência; Uso do Tempo e Diversidade Ecológica e Resiliência.

Cada uma dessas dimensões possibilita uma abertura para a construção coletiva de um rol de ações/possibilidades de atuação que vão compor um PTS formulado em múltiplas dimensões que orienta as ações no Caps.

A felicidade aqui é tomada como uma ética ${ }^{19}$ não normativa, isto é, uma realização possível a partir de um projeto mobilizador para promover e induzir movimentos, mediações e articulações entre os indivíduos da comunidade no território onde habitam, para projetos para a vida e o bem viver, como uma aposta baseada na reflexão do contexto atual da vida, de modos de existência e suas possibilidades.
[...] nem toda ética precisa ser normativa (a de Espinosa, por exemplo, não o é). Uma ética não-normativa é uma ética que estuda as ações e as paixões em vista da felicidade, e que toma como critério as relações entre a razão e a vontade no exercício da liberdade como expressão da natureza singular do indivíduo ético que aspira pela felicidade ${ }^{20(1)}$.

Considerando que a privação e as ameaças dessas dimensões citadas na FIB podem gerar sofrimentos psíquicos, o que se procura legitimar a partir desses fundamentos é a importância de uma atenção e de um cuidado em saúde mental comprometida com o conjunto dessas esferas/dimensões que compõem a pessoa, e mais do que isso, que se desdobrem por uma proposta de reabilitação psicossocial integral, a partir de acolhimento e disponibilidade em receber e ofertar na relação de cuidado, ações articuladas por equipes multiprofissionais e redes intersetoriais que integrem ações preventivas, curativas e de promoção da saúde a sujeitos de direitos e sua comunidade.

\section{A proposta de um PTS com as dimensões da FIB}

A seguir, procuramos apresentar a proposta do PTS construída no Caps-Magal por meio das dimensões da FIB. Dessa forma, com base no referencial teórico já citado e que constituiu a formulação do texto de Kinoshita et al. ${ }^{1} \mathrm{em}$ 2016, pelo qual já se faz uma leitura orientadora das dimensões da FIB aplicadas à atenção psicossocial.

Conforme anteriormente mencionado neste texto, as inovações que se fizeram presentes nos PTS do Caps-Magal e deram na medida em que os trabalhadores foram sendo qualificados para a utilização do PTS por intermédio das dimensões da FIB, nas sessões de educação permanente e supervisão clínico-institucional das reuniões de equipe. Assim, seguiam-se reflexões acerca das dimensões da FIB, e a direção de sua aplicabilidade prática com 
ações e estratégias de cuidado no Caps e no território, sendo mobilizadas e ganhando concretude. Com vistas a enfatizar ainda o caráter multiprofissional e interdisciplinar da proposta das dimensões da FIB no Caps, iremos explicar, de forma sintética, como foi operá-las por meio do PTS por ações objetivas e práticas nos processos de cuidado, tal e qual já vem sendo realizada nessa experimentação no Caps.

\section{$1^{\text {a }}$ Dimensão da FIB: bem- estar psicológico}

A ideia de bem-estar está intrinsecamente ligada a como cada indivíduo percebe sua realidade em um dado contexto. Assim, quando nos referirmos ao bem-estar psicológico, estamos tratando do universo próprio de cada pessoa e de sua subjetividade.

No campo da saúde, é essencial pensar o cuidado de uma forma que considere a pessoa na sua complexidade de modos de vida e existência, envolvendo: possibilidades e limitações pessoais, conflitos, afetos, história de vida, valores constituídos, percepção de futuro, papéis sociais e de participação comunitária, vida secreta, relação com o próprio corpo, entre outros.

Há de se evitar a redução do foco a aspectos nosológicos, restritos à definição de diagnóstico das doenças, que gera um repertório empobrecido, restrito a sintomas, que o usuário relata quando chega ao serviço de saúde, originando de um acordo tácito, próprio da relação entre paciente e profissional de saúde, pautada pelo estabelecimento da função biomédica da cura e eliminação dos sintomas, quase sempre atribuída ao profissional de saúde e ao serviço em que ele atua.

Abaixo, citamos alguns exemplos de ações práticas que podem fazer parte do PTS no Caps:

Estabelecer conversas periódicas com o usuário; entrevistar familiares e sua rede social; discutir com o usuário evolução e efeitos no uso dos fármacos prescritos; discutir e analisar a evolução do usuário com ele e com os demais dispositivos que acompanham o caso; mediar conflitos familiares e/ou entre vizinhos; apresentar ao usuário as atividades que os serviços oferecem; convidar o usuário a participar das ações disponíveis na rede; realizar conversas individuais; buscar conhecer como o usuário se refere a sua vida, se mostra-se otimista ou pessimista; e pensar com ele estratégias que possam ser implementadas para que ele se sinta melhor; análise de fatores de risco e vulnerabilidade.

\section{$2^{\mathrm{a}}$ Dimensão da FIB: padrão de vida e felicidade}

A dimensão padrão de vida e felicidade diz respeito ao nível de acesso a bens e serviços que uma pessoa possui. Isso está relacionado não apenas com os rendimentos financeiros, mas também com a possibilidade de acesso a educação, lazer, cultura, esporte, benefícios, direitos básicos, inclusive o direito à saúde. A garantia de acesso a esses bens e direitos à população indicam fatores de qualidade de vida, e podem orientar estratégias de ação pelo PTS tanto individuais quanto comunitárias.

Na discussão sobre o padrão de vida, apresentam-se três importantes eixos utilizados

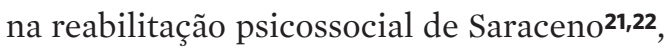
considerados por ele como orientadores do cuidado: o habitar, o trabalho e a rede de suporte social.

O habitar pressupõe a necessidade de pensar o espaço de moradia, avaliar a qualidade dela e qual o poder de negociação desse usuário dentro desse ambiente. Assim, consideramos importante o técnico de referência do caso responsável pela formulação do PTS levar em consideração, nessa dimensão do padrão de vida e felicidade, os seguintes aspectos: situações mais gerais da qualidade da moradia como saneamento básico, coleta de lixos etc., e situações mais específicas, como: se há janelas na casa, se a casa apresenta acabamento, se há separação entre os cômodos, há possibilidade 
de privacidade para os moradores, conhecer como se dão as relações subjetivas no espaço de moradia, entre outros.

O segundo eixo observado por Sarraceno ${ }^{21}$ na reabilitação psicossocial é o trabalho: um dos aspectos importantes no entendimento do contexto de vida de uma pessoa é saber como ela relaciona-se com seu trabalho e sua renda. Ademais, sabe-se que o acesso das pessoas com a experiência do sofrimento psíquico ao mercado de trabalho formal ainda é baixo, por isso, fomentar projetos de geração de trabalho e renda e economia solidária é importante estratégia para a promoção da cidadania dessas pessoas, além disso, tais projetos potencializam a vitalidade comunitária, outra importante dimensão da FIB e do bem viver, e devem fazer parte do PTS.

$\mathrm{O}$ terceiro eixo a que Saraceno ${ }^{\mathbf{2 1}}$ se refere, a rede social de suporte, trata de um aspecto que está estreitamente relacionado com a qualidade do padrão de vida. Contudo, optou-se por trabalhá-lo na dimensão vitalidade comunitária, a fim de respeitar a lógica e a divisão dos domínios propostos pela FIB.

Citamos, a seguir, alguns exemplos de ações que podem constar do PTS: estimular discussões em espaços comunitários sobre condições de vida no bairro e sobre possíveis melhorias; realizar encontros de aproximação com movimentos sociais que discutam moradia, trabalho, educação, cultura e estratégias de cuidado, procurando fortalecê-los, reinserção laboral por projetos de economia solidária e geração de trabalho e renda; conversar com o usuário sobre o seu habitar.

\section{$3^{a}$ Dimensão da FIB: a boa governança}

Essa dimensão diz respeito à participação dos cidadãos nas decisões e processos políticos nas esferas acessíveis à pessoa - território/ comunidade, bairro, município, estado, país. O fortalecimento da vitalidade comunitária e da democracia está intimamente ligado à governança, e trata de um exercício que pode e deve ser praticado por todos.

Na sequência, sugerimos algumas ações que podem ser inseridas no PTS para essa dimensão da FIB: assembleias de usuários para discussão de funcionamento do Caps ou outro ponto de atenção da Raps; criação de conselho gestor do serviço com a participação de usuários e familiares; abertura de espaços coletivos, dentro e fora do serviço, para a discussão das questões que mais afligem a comunidade; participação dos usuários no conselho distrital e ou municipal de saúde; inclusão de usuários em conselhos comunitários e associações de moradores, entre outros.

Outros exemplos de ações nessa dimensão da FIB no PTS - identificar: os espaços de atuação política existentes; os recursos - educação, assistência social, saúde disponíveis e como atuam no território; as associações, os conselhos, comitês, partidos políticos que atuam no território; as ações coletivas de participação do usuário com esses grupos; a ampliação das possibilidades de viver e circular pelo território.

\section{4ª Dimensão da FIB: saúde}

O cuidado psicossocial se traduz pela aproximação às subjetividades que se produzem no indivíduo, sua família e comunidade no território onde habita. Aqui, propõe-se que o cuidado possa gerar movimentos e trocas no sentido de potencializar os indivíduos a tornarem-se cada vez mais autônomos e capazes de fazer escolhas. Essas serão melhores quanto mais possível for o compartilhamento das responsabilidades entre profissional de saúde, usuários dos serviços, as famílias, a comunidade, a rede de saúde e a rede intersetorial.

Exemplos de ações nesse domínio da FIB: traçar com o usuário um PTS que leve em conta as dimensões orgânicas de sua demanda como interligadas ao sofrimento psíquico; considerar o sofrimento psíquico e a experiência subjetiva como elemento essencial em todas as consultas 
e grupos oferecidos na unidade; orientar para atendimento no Caps e na Raps; compartilhar o cuidado do usuário com outros profissionais de saúde da equipe EqSF/Nasf (nutricionista, dentista, médico, psicólogo, outros); orientar, avaliar e monitorar periodicamente a evolução clínica e psicossocial do usuário; acompanhar adesão e processo do tratamento farmacológico, incluindo casos de dependência ao medicamento, orientar familiares quanto a supostos riscos à integridade física do usuário, estabelecendo uma rede de proteção a danos, entre outros.

\section{$5^{\text {a }}$ Dimensão da FIB: educação}

Os profissionais de saúde da Raps devem ser agentes propagadores de saberes ligados ao conceito de bem viver na comunidade. Isso significa dizer que faz parte de suas atribuições conhecer os modos como as pessoas vivem, seus hábitos, suas verdades, seus costumes, sua cultura, e, assim, trabalhar com elas na consolidação de um território e de uma comunidade que produzam mais qualidade de vida. Tal tarefa não é simples no cotidiano dos serviços, pois, de maneira geral, valoriza-se o saber científico em detrimento dos saberes vindos da comunidade.

Os grupos de pessoas que compõem o conjunto de uma comunidade possuem saberes diversificados acerca dos vários domínios da vida (família, trabalho, saúde, amizade, comunidade, prazer, educação, saber, cultura, arte etc.). As pessoas aprendem com seus parentes mais próximos, seus vizinhos, seus colegas e amigos a lidar com as situações cotidianas. Isso é educação, é troca interpessoal em que as pessoas compartilham saberes e experiências.

Exemplos de ações nesse domínio da FIB no PTS: identificar locais e pessoas importantes para o desenvolvimento histórico e cultural da comunidade; convidar membros da comunidade a dividir seus conhecimentos; atuar para a educação que visa o bem viver e a promoção da cidadania; identificar locais onde os saberes científicos estão sendo desenvolvidos; locais onde acontecem reuniões de fortalecimento de vínculos; espaços públicos e abertos ao público que fomentem a vida cultural e educacional na comunidade; promover discussão de projetos que promovam a maior participação dos sujeitos nos diversos espaços da comunidade, visando ao desenvolvimento das suas potencialidades humanas e sociais; identificar e contribuir para a formação de lideranças comunitárias.

\section{$6^{\mathrm{a}}$ Dimensão da FIB: vitalidade comunitária}

A Raps atua em territórios adscritos de comunidades com uma ampla diversidade de características que singularizam contextos sociais e a identidade comunitária. O lócus social no qual a vida acontece é composto por relacionamentos afetivos, trocas de experiências e saberes da realidade, seus problemas mais comuns, as soluções encontradas e que mobilizam a comunidade a enfrentá-los.

Os interesses compreendidos nesse domínio preveem garantia de direitos e de cidadania dos sujeitos que compõem coletivos, fortalecimento de ações no território e acesso comum aos benefícios comunitários, dissolvendo assim os privilégios particulares.

Exemplos de ações nesse domínio da FIB no PTS: valorizar estratégias que possibilitem busca ativa de indivíduos em isolamento social dentro do território para assisti-los e inseri-los nas ações programadas pela Raps; instituir a promoção de fóruns permanentes que discutam a saúde no território com usuários, profissionais, gestores afins e todos demais atores correlatos; utilizar programas de transferência de renda e outros benefícios sociais como estratégia de resgate da cidadania e da inclusão social; buscar a (re)aproximação de usuários a grupos de amigos, familiares, vizinhos e centros de convivência, fortalecendo a rede de apoio social; criar grupos de vizinhança 
solidária, em que vizinhos possam compartilhar seus problemas e ajudar-se mutuamente; organizar espaços entre pais/cuidadores do território de forma que possam conhecer e confiar uns nos outros, dividindo tarefas de cuidado às crianças; organizar grupos de cuidadores de idosos e acamados.

\section{$7^{\mathrm{a}}$ Dimensão da FIB: diversidade cultural e resiliência}

A promoção da cultura é um aspecto vital da FIB. A cultura tradicional das comunidades é expressa de diversas formas: histórias locais, hábitos e costumes, arte, modos de vida e de existência devem ser valorizadas e preservados. Em uma comunidade, os seus moradores têm formas e meios de vida que devem ser protegidos e respeitados. Dessa forma, podemos influenciar no sentimento de pertencimento da cultura na qual o indivíduo está inserido, aumentando sua autoestima.

Exemplos de ações nesse domínio da FIB no PTS: promover inclusão de usuários na cultura local; divulgar a cultura local; promover eventos culturais e comunitários; intervir na realidade cultural do território; realizar rodas de conversa sobre temas culturais, saraus poéticos e musicais no Caps; promover festas folclóricas; rodas de capoeira; programação de passeios a teatros, cinemas, museus com os usuários;

\section{$8^{\text {a }}$ Dimensão da FIB: uso do tempo}

Na perspectiva da FIB, o tempo e o valor de seu uso exercem significativa importância para produção de vida no território, contemplando assim o indivíduo, a família e a comunidade.

A vida contemporânea, marcada pelo crescente automatismo do cotidiano e pela alta necessidade de consumo, tem favorecido um tipo de relação em que os sujeitos são reféns do seu próprio tempo. Como consequência, induzem certa emergência e imediatismo na vida cotidiana, que se traduzem em precipitações nas ações e reações das pessoas; e como desdobramentos, o que vemos, principalmente nos grandes centros urbanos, é uma aceleração no andar a vida e o mau uso do tempo como consequência.

Contudo, o mau uso do tempo não acontece somente pelo excesso de atividades. Em muitas comunidades, ocorrem problemas decorrentes da quase ausência de ofertas de atividades para ocupação do cotidiano, e aqui não se defende a ocupação somente pelo cuidado, mas a possibilidade de ofertar atividades que tenham como objetivo oferecer espaços de pertencimento e desenvolvimento comunitário. Apresentam-se como maior público nessa situação os adolescentes, os desempregados e os idosos.

Ademais, se o excesso de atividades e a aceleração da vida podem produzir quadros de sofrimentos mentais, como a ansiedade, a inquietação, a euforia e o pânico, a ociosidade pode produzir a letargia, a depressão, o desânimo e a falta de perspectiva de vida.

Acionar e despertar os indivíduos para darem valor de uso ao seu tempo podem ter um potencial terapêutico considerável, não só para sua própria saúde, mas também para a sua comunidade, promovendo qualidade de vida nesse território e adicionando aspectos que favoreçam projetos para a felicidade no coletivo.

Exemplos de ações nesse domínio: discutir em equipe o levantamento de dados e características singulares do território quanto à dinâmica de vida na comunidade e o uso do tempo; realizar rodas de conversa com grupos específicos (mulheres, adolescentes, idosos); propiciar ações que visem à boa gestão do uso do tempo; promover ou potencializar espaços de brincar compartilhado entre as crianças e adolescentes do bairro, priorizando o uso do espaço público; identificar as situações de vulnerabilidade e potencialidades relativas a questões de gênero, faixa etária e o bom uso do tempo no território. 


\section{9a Dimensão da FIB: diversidade ecológica e resiliência}

Essa dimensão da FIB se relaciona com o meio ambiente no qual se vive e as formas de preservação e renovação da ecologia local. Devem-se considerar, nesse aspecto, as formas de habitar e viver no território, e as consequências de desequilíbrios ambientais causados muitas vezes por ocupações irregulares na comunidade.

Essa realidade pode se traduzir em problemas de saneamento básico sem tratamento de água e esgoto, depredação de florestas e matas ciliares, erosão de encostas com riscos de desabamentos e deslizes de terra, acúmulo de lixo sem tratamento, casas insalubres e inadequadas, entre outros.

A diversidade ecológica pode promover ações de vigilância ambiental e sanitária com objetivos de prevenir e controlar danos ao meio ambiente local. Exemplos de ações dessa dimensão da FIB: ações que estimulem reflexões sobre forma de habitar na sua moradia (convivência, divisão de espaços, bem estar, ambiência); ações no território de revitalização de espaços comunitários e públicos; contenção de encostas; ações de saneamento básico; coleta seletiva de lixo, entre outros.

\section{Conclusões}

Revisitando as origens que inspiraram os primeiros PTS nos primórdios da reforma psiquiátrica brasileira, acompanhamos os avanços do modelo de atenção psicossocial na superação do manicômio como local de asilar e tratar a loucura.

A ampliação da Raps de base comunitária, substitutiva ao hospital psiquiátrico e funcionando por meio de dispositivos e estratégias para o cuidado em liberdade, vem produzindo inovações que impactam sobremaneira na promoção de saúde mental; e na reabilitação and Contributor ID). psicossocial, na inclusão de usuários com transtornos mentais graves e persistentes.
O PTS como tecnologia de cuidado largamente utilizada no campo da saúde mental é um vetor importante para potencializar projetos para a vida, a serem construídos e protagonizados pelo usuário com sofrimentos psíquicos. Assim, o sujeito vai-se reconhecendo na medida em que é estimulado a conviver em liberdade e pelo fortalecimento de laços afetivos e sociais, assumindo gradualmente suas escolhas e decisões e adquirindo mais autonomia e condução de sua própria existência.

A FIB fala de sustentabilidade, e para, de fato, torná-la mais perene, é importante o aprofundamento de estudos e pesquisas acerca dos dispositivos e ofertas de cuidado psicossocial para a promoção da felicidade pública e do bem viver. Métodos de pesquisa que busquem cartografar a evidência da produção dessas novas subjetivações, podem ampliar assim o campo do saber e do fazer da atenção psicossocial, com apostas em projetos para a vida dos usuários da Raps do SUS, e formulação de políticas públicas inovadoras que promovam novos modos de existência e de felicidade coletiva.

Assim, a FIB e suas nove dimensões tratadas neste artigo na perspectiva de serem os eixos componentes na formulação de um modelo de PTS demonstraram, com a experimentação deste estudo, poderem promover diversas ações para o cuidado e projetos para a vida dos usuários com transtornos mentais persistentes. Dessa forma, pode ampliar ainda mais a atenção psicossocial como uma ética de cuidado pautada pela promoção de autonomia, pela garantia de direitos e pelo conceito de bem viver.

\section{Colaboradores}

Kinoshita RT (0000-0003-1599-6202)*, Trino AT (0000-0003-1762-4795)*, Guimarães CS (0000-0003-2717-381X)*, Castro CA (00000002-0769-9008)*, Prado CMAS (0000-00033038-1695)* contribuíram igualmente para a elaboração do manuscrito. 


\section{Referências}

1. Alcântara LCS, Sampaio CAC. Bem Viver como paradigma de desenvolvimento: utopia ou alternativa possível. Rev. Desenvolv. Meio Ambiente. 2017; 40(3):231-251.

2. Kinoshita RT, Trino AT, Barreiros CA, et al. Cuidado em Saúde Mental: do Sofrimento à Felicidade. In: Nunes M, Landim FLP. Saúde Mental na Atenção Básica - Política e Cotidiano. Salvador: EDUFBA; 2016. p. $47-77$.

3. Law J, Mol A. Notes on Materiality and Sociality. The Sociological Review. 1995; 43(2):274-294.

4. Latour B. Science in Action: How to follow Scientists and Engineers through Society. Cambridge: Harvard University Press; 1987.

5. Orlikowski WJ. Sociomaterial practices: technology at work. Organization Studies. 2007; 28(9):1435-1448.

6. Orlikowski WJ, Scott SV. Sociomateriality: Challenging the Separation of Technology, Work and Organization. Acad. Manag. Ann. 2008; 2(1):433-474.

7. Leonardi PM. Materiality, Sociomateriality, and Socio-technical Systems: What Do These Terms Mean? How Are They Different? Do We Need Them? In: Leonardi PM, Nardi BA, Kallinikos J, editores. Materiality and Organizing: Social Interaction in a Technological World. Oxford: Oxford University Press; 2012.

8. Trino A, Guimarães MC, Kinoshita RT. Projeto terapêutico singular pelas dimensões da Felicidade Interna Bruta (FIB). Repositório do observatório do cuidado. Fevereiro de 2020 [acesso em 2020 fev 7]. Disponível em: https://repositorio.observatoriodocuidado.org/handle/handle/2700.

9. Singer P. A iniciativa que veio do Himalaia. Folha de São Paulo, 29 de abril de 2012. Sessão: opinião, p. 5. [acesso em 2018 nov 17]. Disponível em: https://web. archive.org/web/20160925190104/http://wwwl.folha.uol.com.br/fsp/opiniao/39911-a-iniciativa-que-veio-do-himalaia.shtml.
10. Rio de Janeiro. Secretaria Municipal de Saúde, Coordenação de Área Programática 3.1, CAPS Magal. Projeto Técnico e Político Institucional do Centro de Atenção Psicossocial tipo II Carlos Augusto Magal. Rio de janeiro; 2016.

11. Galeffi D. Prefácio. In: Macedo R. A pesquisa e o acontecimento: compreender situações, experiências e saberes acontecimentais. Salvador: EDUFBA; 2016, p. 17.

12. Lustosa AE, Melo LF. Felicidade Interna Bruta (FIB) - Índice de Desenvolvimento Sustentável. [acesso em 2020 out 12]. Disponível em: http://base.socioeco.org/docs/artigo05.pdf.

13. Ura DK. Felicidade Interna Bruta. In: $1^{\text {a }}$ Conferência Nacional do FIB - São Paulo, 2008. [acesso em 2020 out 12]. Disponível em: http://www.dhnet.org.br/direitos/indicadores/felicidade/dasho_karma_explica fib.pdf.

14. O'Donnell G. Using Well-Being as a Guide to Policy. In: Helliwell J, Layard R, Sachs J. The World Happiness Report: 2013. Nova York: Earth Institute; 2013.

15. Nery PF. Economia da Felicidade: implicações para Políticas Públicas. Brasília (DF): Núcleo de Estudos e Pesquisas; 2014. (Texto para Discussão n. 156). [acesso em 2018 maio 20]. Disponível em: https://www12. senado.leg.br/publicacoes/estudos-legislativos/tipos-de-estudos/textos-para-discussao/td156.

16. Stiglitz J. Em Busca de um novo Paradigma para o Desenvolvimento: estratégias, políticas e processos. Genebra: (In) UNCTAD;1998.

17. Sen A, Stiglitz J. (Mis) Measuring our lives: why GDP doesn't add up. New York: The New Press; 2010.

18. Sarraceno B. A Return to the Way leading to Hapiness. 2012. [acesso em 2015 jul 28]. Disponível em: http://www.souqonline.it/home2_2_eng. asp?idpadre $=865 \&$ idtesto $=856$. 
19. Espinoza B. Éthique. Paris: GF Flammarion; 1965

20. Chauí M. Ensaio: Ética e Violência. 1998. [acesso em 2020 jan 17]. Disponível em: http://csbh.fpabramo. org.br/o-que-fazemos/editora/teoria-e-debate/edicoes-anteriores/ensaio-etica-e-violencia.

21. Saraceno B. Reabilitação psicossocial: uma estratégia para a passagem do milênio. In: Pitta AM, organizadora. Reabilitação psicossocial no Brasil. São Paulo: Hucitec; 1996. p. 13-18
22. Saraceno B. Libertando identidades: da reabilitação psicossocial à cidadania possível. 2. ed. Belo Horizonte: Te Corá; Rio de Janeiro: Instituto Franco Basaglia; 2001.

Recebido em 05/02/2020 Aprovado em 21/07/2020

Conflito de interesses: inexistente

Suporte financeiro: não houve 